\title{
ISOLASI DAN KARAKTERISASI CENDAWAN DEKOMPOSER PADA BAHAN KOMPOS JERAMI, ENDAPAN TANAH DANAU TEMPE DAN TANAH EXFARM PERTANIAN UNIVERSITAS HASANUDDIN
}

\author{
Isolation and Characterization of Fungal Decomposers in Compost Straw Materials, \\ Sediment Soil from Tempe Lake and soil from agricultural exfarm Hasanuddin University \\ ${ }^{1 *}$ Fatmawati, ${ }^{2}$ Burhanuddin Rasyid, ${ }^{2}$ Muh. Jayadi \\ ${ }^{1}$ Alumni Departemen Ilmu Tanah, Fakultas Pertanian, Universitas Hasanuddin, \\ ${ }^{2}$ Departemen Ilmu Tanah, Fakultas Pertanian, Universitas Hasanuddin \\ *Corresponding email: titifatmawati901@gmail.com
}

\begin{abstract}
Agricultural wastes able to provide profit value if utilized properly for example made into organic fertilizer. Organic fertilizer production requires microbial decomposers to help the decomposition process. This research aims to isolate and identify the characteristics of microbial decomposers found in straw compost, soil sediment from tempe lake and soil from exfarm. In this research, conducted microbial isolation. Microbial exploration of compost material, soil organic matter and soil deposition material is mixed with physiological solution then grown on PDA, further purification of the unwanted microbes. In this study only used the media to grow the asparagine fungus to see the growth of macroscopic and microscopic fungi. The results showed that there are seven isolates of the fungus from different material extraction. The extracted compost material to produce two fungi are Aspergillus sp. and Penicillium sp., Tempe lake sediment soil shows three types of fungi with Aspergillus Sp. and two types Zygomisota, while soil from Exfarm also shows two types of fungi are Aspergillus sp. and Penicillium sp. The growth rate of each different fungal isolates based sources although of the same type.
\end{abstract}

Keywords: Straw compost, decomposers fungus, Aspergillus sp., Penicillium sp., Zygomisota

\section{PENDAHULUAN}

Limbah pertanian yang berlimpah merupakan suatu bahan yang mempunyai nilai tambah bila diproses lebih lanjut, diantaranya digunakan sebagai bahan pembuatan pupuk organik. Sebagai contoh, adalah jerami yang berasal dari limbah pertanaman padi. Limbah ini, dapat dimanfaatkan secara efektif dengan memberi perlakuan yang tepat. Rata-rata produktivitas padi nasional adalah 48,95 $\mathrm{ku} / \mathrm{ha}$, sehingga jumlah jerami yang dihasilkan kurang lebih 68,53 ku/ha. Produksi padi nasional tahun 2008 sebesar 57,157 juta ton (Deptan dalam Mulyadi 2008), dengan demikian produksi jerami nasional diperkirakan mencapai 80,02 juta ton. Potensi jerami yang sangat besar ini sangat banyak yang masih disia-siakan oleh petani. Sebagian besar jerami hanya dibakar menjadi abu yang dampaknya adalah pencemaran lingkungan. Berdasarkan beberapa peninjauan mengenai diabaikannya limbah jerami, maka perlu dikaji pentingnya pemanfaatan limbah jerami.

Untuk pengomposan jerami, dilakukan proses pencampuran dengan beberapa bahan lainnya. Mikroorganisme di perlukan pada pembuatan kompos sebagai aktivator yang berperan untuk mendegradasi jerami dalam waktu singkat. Pada pengomposan ada juga yang disebut sebagai biodekomposer, yaitu organisme pengurai nitrogen dan karbon dari bahan organik (sisa-sisa organik dari jaringan tumbuhan 
atau hewan yang telah mati) yaitu bakteri, fungi, dan aktinomisetes. Menurut (Eriksson et al. 1989 dalam Saraswati, 2005), umumnya kelompok fungi menunjukkan aktivitas biodekomposisi paling signifikan, dapat segera menjadikan bahan organik tanah terurai menjadi senyawa organik sederhana yang berfungsi sebagai penukar ion dasar yang menyimpan dan melepaskan nutrien di sekitar tanaman.

Penelitian ini bertujuan untuk mengisolasi dan mengetahui mikroba yang terdapat pada kompos jerami, endapan tanah danau Tempe dan tanah exfarm. Serta mengetahui karakteristik cendawan dekomposer yang ditemukan. Kegunaan penelitian ini adalah mempermudah pengomposan karena dihasilkannya aktivator dari isolat mikroba dekomposer. Selanjutnya hasil penelitian ini dapat digunakan dalam mengelola limbah pertanian menjadi bahan yang lebih bermanfaat.

\section{METODE PENELITIAN}

Penelitian ini dilaksanakan di rumah kaca, di Laboratorium Mikrobiologi Tanah, Jurusan Ilmu Tanah Fakultas Pertanian, dan Laboratorium Penyakit Jurusan Ilmu Hama dan Penyakit Fakultas Pertanian Universitas Hasanuddin. Penelitian berlangsung mulai November 2014 hingga September 2015.

Mikrobaiseppengomposan dimulai dengan mencampur potongan jerami dan serbuk gergaji dengan perbandingan $6: 4$ yang kemudian disebut campuran 1. Pada wadah lain, kotoran ayam dicampur dengan sekam dan kapur dengan perbandingan 10 : 1 selanjutnya disebut campuran 2 .

Sebelum itu, terlebih dahulu kotak diberi alas potongan bambu di dalamnya kemudian meletakkan jerami yang tidak dipotong- potong (jerami kering) diatas potongan bambu tersebut, kemudian disiram dengan air yang sebelumnya dilarutkan pupuk urea dengan perbandingan $10 \mathrm{~g}$ urea : $1000 \mathrm{ml}$ air.

Campuran 2 dihamparkan diatas jerami kering tersebut setebal $5 \mathrm{~cm}$, di atasnya dihamparkan pula campuran 1 setebal $5 \mathrm{~cm}$, kemudian disiram dengan air yang telah diberi EM4. Lalu, diatasnya ditutupi dengan jerami yang tidak dipotongpotong (jerami kering). Selanjutnya 2-3 genggam tanah ditaburi rata diatasnya, kemudian disiram kembali dengan air larutan pupuk urea. Demikian berturut-turut hingga tersusun tiga lapisan, selanjutnya menutup kotak tersebut. Setiap dua minggu suhu dari pengomposan tersebut diukur dengan menggunakan thermometer lalu kompos dibalik.

Pembuatan media PDA dimulai dengan kentang dikupas kulitnya, dipotongpotong kecil lalu ditimbang sebanyak $200 \mathrm{~g}$ kemudian direbus hingga mendidih lalu ekstrak kentang tersebut dimasukkan ke dalam labu erlenmeyer. Pada Erlenmeyer yang berisi ekstrak kentang tersebut di beri gula sebanyak $20 \mathrm{~g}$ dan agar-agar sebanyak $15 \mathrm{~g}$ kemudian dihomogenkan dengan menggunakan hot plate. Pada bagian bibir Erlenmeyer ditutup rapat dengan menggunakan alumunium foil, selanjutnya medium disterilkan dalam autoclave selama kurang lebih satu jam dengan menggunakan suhu $121{ }^{\circ} \mathrm{C}$.

Setelah disterilkan media tersebut ditunggu sampai hangat, kemudian dituang kedalam cawan petri yang telah disterilkan. Media tersebut ditunggu hingga padat, lalu ditutup dengan menggunakan wrapping plastic. Selanjutnya, dibalik untuk menghilangkan uap yang ada pada media tersebut yang berfungsi untuk menghindari terjadinya kontaminasi. Setelah itu, ditunggu beberapa hari untuk melihat apakah media tersebut bisa digunakan.

Pembuatan Larutan Fisiologis dimulai dengan memasukkan aquades ke dalam Erlenmeyer sebanyak $1000 \mathrm{ml}$, lalu timbang $\mathrm{NaCl}$ sebanyak 8,5 g dengan menggunakan timbangan analitik, kemudian masukkan ke dalam erlenmeyer yang berisi $1000 \mathrm{ml}$ aquades, lalu homogenkan.

Suspensi sampel dilakukan dengan memasukkan larutan fisiologis sebanyak 
$150 \mathrm{ml}$ dan sampel kompos kering udara sebanyak $15 \mathrm{~g}$ ke dalam mesin blender, lalu blender hingga halus. Kemudian pindahkan ke dalam Erlenmeyer dengan cara disaring dengan menggunakan corong dan kertas saring whatman.

Penumbuhan mikroba dilakukan dengan cara memasukkan aquades kedalam tabung reaksi sebanyak $9 \mathrm{ml}$ untuk setiap tabung reaksi dengan menggunakan delapan tabung reaksi, kemudian menutup bagian atas tabung reaksi dengan menggunakan alumunium foil. Lalu disterilkan dengan menggunkan autoclave selama kurang lebih satu jam dengan suhu $121{ }^{\circ} \mathrm{C}$. Kemudian air steril tersebut didiamkan sampai dingin.

Jika telah dingin, Selanjutnya mengambil sampel tanah hasil penyaringan sebanyak $1 \mathrm{ml}$ untuk dimasukkan kedalam tabung reaksi yang berisi aquades steril tersebut dengan perpangkatan $10^{-1}$ kemudian dihomogenkan dengan menggunakan vortex. Lalu $10^{-1}$ dipindahkan ke $10^{-2}$ sebanyak $1 \mathrm{ml}$ dengan menggunakan pipet ovendorf.

Mikroba yang sudah tumbuh di media PDA dipindahkan dengan menggunakan jarum oshe ke media baru, agar tidak tercampur dengan mikroba lain sehingga diperoleh mikroba yang murni.

Media asparagin dibuat sebagai media spesifik bagi fungi yang bekerja mengurangi Lignin. Media asparagin ini dibuat dengan cara memasukkan $10 \mathrm{~g}$ agaragar, $0,5 \mathrm{~g} \quad\left((\mathrm{NH} 4)_{2} \mathrm{SO}_{4}, \quad 0,5 \mathrm{~g} \quad \mathrm{~L}-\right.$ Asparagine, $\quad 1,0 \quad \mathrm{~K}_{2} \mathrm{HPO} 4, \quad 0,2 \quad \mathrm{~g}$ $\mathrm{MgSO}_{47 \mathrm{H}} 2 \mathrm{O}, 0,5 \mathrm{~g} \mathrm{KCL}, 0,1$ g CaCl $2,0,5$ $\mathrm{g}$ Ekstrak ragi, dan $10 \mathrm{~g}$ Selulosa (filter paper strips) kedalam Erlenmeyer, lalu masukkan aquades sebanyak $500 \mathrm{ml}$, kemudian homogenkan dan di autoclave selama 1 jam.

\section{HASIL DAN PEMBAHASAN}

\section{Isolasi dan Karakterisasi Cendawan Dekomposer}

Hasil isolasi cendawan dari tiga sampel yaitu, kompos jerami, tanah exfarm dan endapan tanah danau tempe, maka di peroleh 7 isolat cendawan yang terdiri dari 3 isolat endapan tanah danau tempe, 2 isolat dari tanah exfarm dan 2 isolat dari kompos jerami yang dibuat. Adapun 7 jenis isolat berdasarkan karakterisasi cendawan tersebut yaitu terdiri dari Aspergillus sp., Penicillium sp., dan zygomicota yang tersaji pada Tabel 1 dan 2.

Tabel 1. Jumlah dan jenis cendawan

\begin{tabular}{ccc}
\hline Sumber Isolat & Jenis koloni & Jenis cendawan \\
\hline Kompos & 2 & $\begin{array}{c}\text { Aspergillus sp. } \\
\text { Penicillium sp. }\end{array}$ \\
\hline Endapan Tanah Danau & 3 & $\begin{array}{c}\text { Zygomicota } \\
\text { Tempe }\end{array}$ \\
Tanah Exfarm & 2 & Aspergillus sp. \\
\hline Penicillium sp. \\
\hline
\end{tabular}

Dari ke-3 sumber isolat terlihat bahwa Aspergillus.sp dan Penicillium.sp merupakan cendawan yang umum ditemukan, terlihat dari terdapatnya aspergillus sp. di setiap jenis sumber isolat dan Penicillium sp. yang terdapat di 2 sumber isolate. Hal ini sesuai dengan yang dikemukakan oleh (Abadi AL, 2003 dalam Lina Budiarti. 2014) bahwa Pennicillium sp., dan Aspergillus sp. merupakan jamur yang umum terdapat dalam tanah, tumbuh dengan cepat dan bersifat antagonistic terhadap jamur lain. Mekanisme antagonis jamur tersebut terjadi dengan cara kompetisi, mikoparasitik, dan antibiosis. Biakannya dapat diperoleh dengan cara mengisolasi dari tanah. 
Tabel 2. Karaktersitik cendawan pada berbagai sumber isolat yang ditemukan selama penelitian.

\begin{tabular}{cccc}
\hline Sumber isolate & Jenis cendawan & $\begin{array}{c}\text { Laju pertumbuhan } \\
\text { (memenuhi cawan) }\end{array}$ & Warna koloni \\
\hline Kompos & Aspergillus sp. & 8 hari & Puth \\
& Penicillium sp & 24 hari & Hijau tua \\
\hline & Zygomicota 1 & 16 hari & $\begin{array}{c}\text { Puth, diselingi } \\
\text { coklat kehitaman }\end{array}$ \\
Endapan Tanah & Zygomicota 2 & 20 hari & $\begin{array}{c}\text { Putih diselingi } \\
\text { kuning muda }\end{array}$ \\
Danau Tempe & Aspergillus sp & 44 hari & \begin{tabular}{c} 
coklat \\
\hline Tanah Exfarm
\end{tabular} \\
& Penicillium sp. & 40 hari & $\begin{array}{c}\text { Hijau diselingi } \\
\text { putih }\end{array}$ \\
& Aspergillus sp. & 24 hari & Hijau tua \\
\hline
\end{tabular}

\section{Aspergillus sp.}

Berdasarkan hasil pengamatan mikroskopis dan makroskopis (Gambar 1 - 3) diketahui bahwa Aspergillus sp. memiliki keragaman warna koloni, yaitu putih, cokalt dan hijau tua kecoklatan. Jika dilihat secara makroskopis diketahui bahwa konidiofor tegak, konidia bulat dan pada ujung konidiofor terjadi pembengkakan berbentuk bulat. Hal ini sesuai dengan Barnett dan Hunter (1998), bahwa Aspergillus sp. Memiliki konidiofor tegak, sederhana dan pada ujungnya membentuk globose (hampir membentuk bola) atau clavate (berbentuk pentungan).

Bernett 1955) dalam Ihwan 2015 menyatakan bahwa tangkai konidiofor (stipe) tidak berornamentasi/berdinding halus dan berwarna transparan (hialin). Kepala konidia berwarna hitam dan berbentuk bulat hingga semi bulat, berwarna coklat tua.
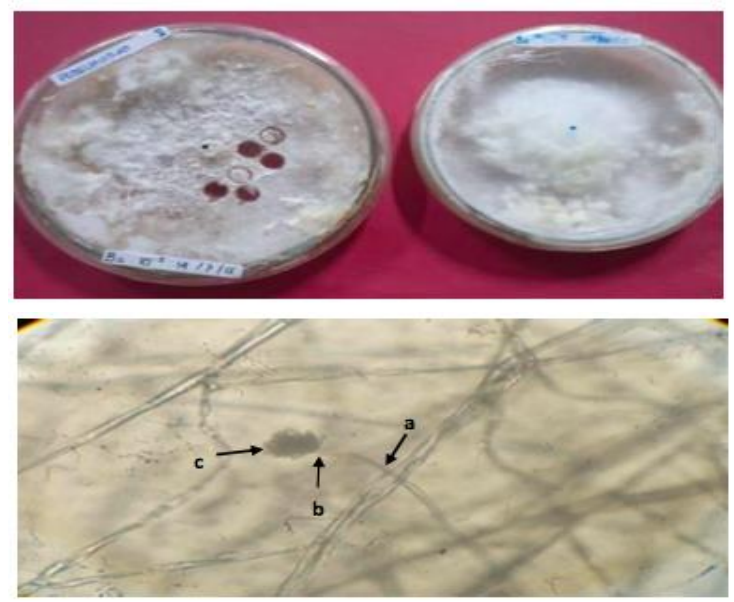

Gambar 1. Aspergillus sp. pada kompos (a. konidiofor, b. konidia, c. spora)
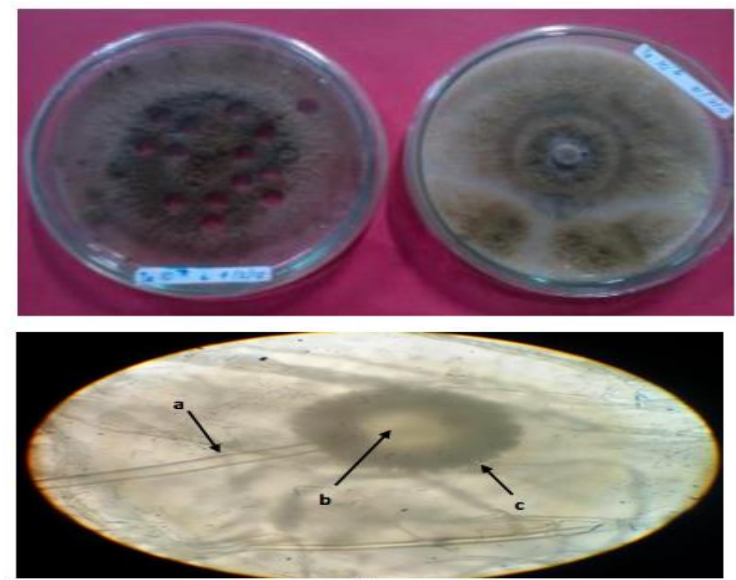

Gambar 2. Aspergillus sp. pada tanah danau Tempe (a. konidiofor, b. konidia, c. spora)
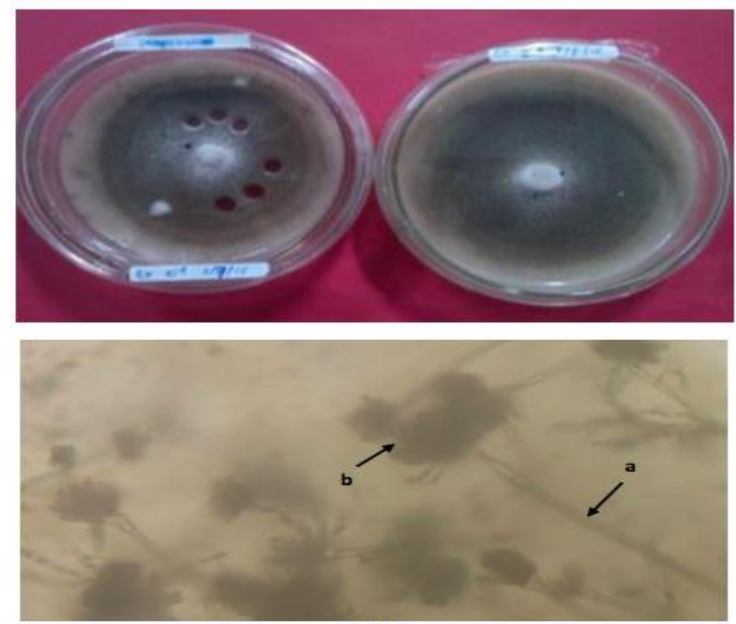

Gambar 3. Aspergillus sp. pada tanah exfarm (a. konidiofor, b. spora). 
Konidia berbentuk dari fialid yang menumpang pada metula (tipe biseriate) dan membentuk formasi sikat melingkar (radiate columnar).

\section{Penicillium sp.}

Berbeda dengan Aspergillus, pada Penicillium sp., hasil pengamatan mikroskopis dan makroskopis (Gambar 4 5) nampak koloni memiliki keragaman warna berupa hijau tua, dan hijau diselingi putih. Bentuk morfologi dari penicillium sp., dengan bentuk tangkai hifa percabangan, diujung terdapat konidiofor yang menjari. (Barnett dan Hunter, 1998) menyatakan bahwa cendawan penicillium sp., secara mikroskopis memiliki bentuk konidiofor yang khas. Konidiofor muncul tegak dari miselium, sering berbentuk seinnemata dan bercabang mendekati ujungnya. Ujung konidiofor memiliki sekumpulan fialid dengan konidia berbentuk globus atau ovoid, tersusun membentuk rantai basipetal.

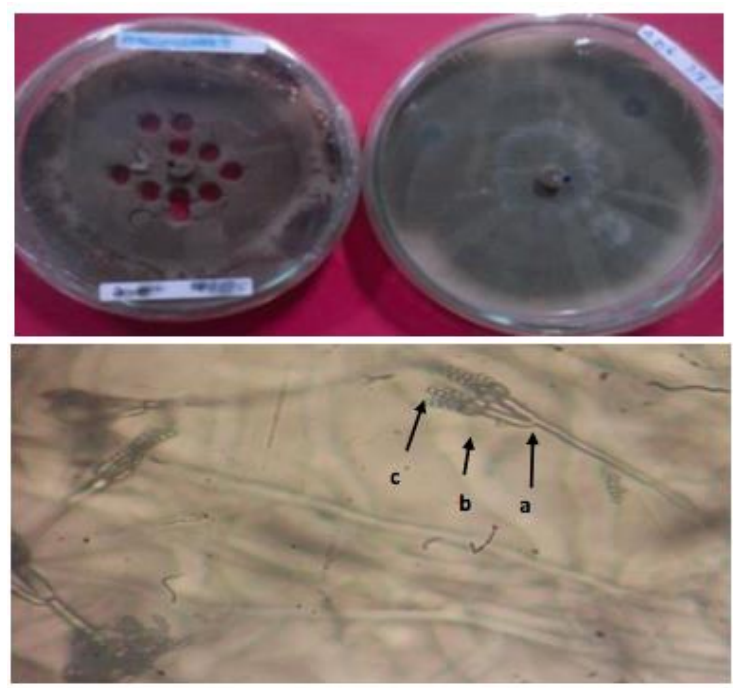

Gambar 4. Penicillium sp pada kompos.

\section{Zygomycota 1.}

Berdasarkan hasil pengamatan makroskopis dan mikroskopis (Gambar 6) diketahui bahwa zygomisota memiliki keragaman warna koloni yaitu putih diselingi coklat kehitaman dan putih diselingi kuning muda.
Jika dilihat secara mikroskopis zygomicota mempunyai miselium, spora yang terdapat didalam sporangium. Serta hifa yang tidak mempunyai septa.
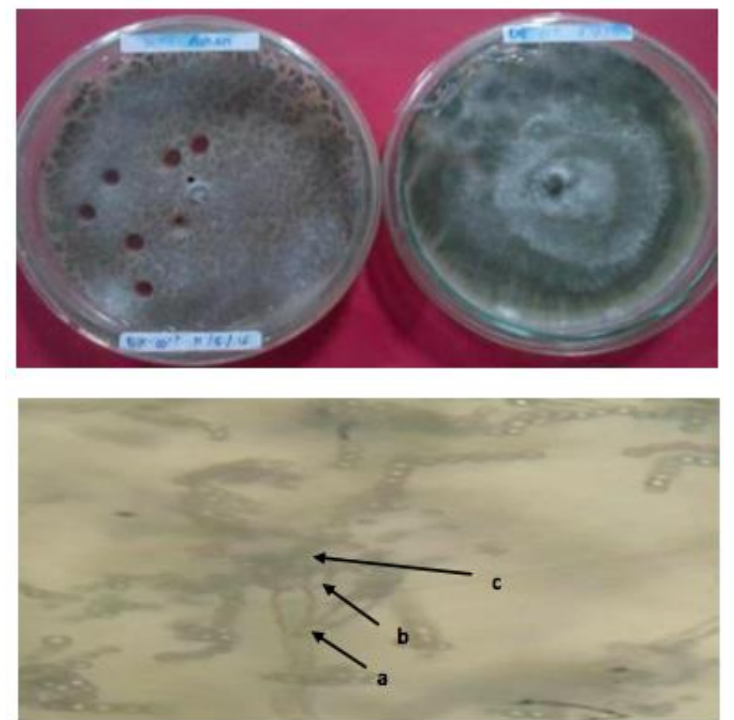

Gambar 5. Penicillium sp pada tanah exfarm.
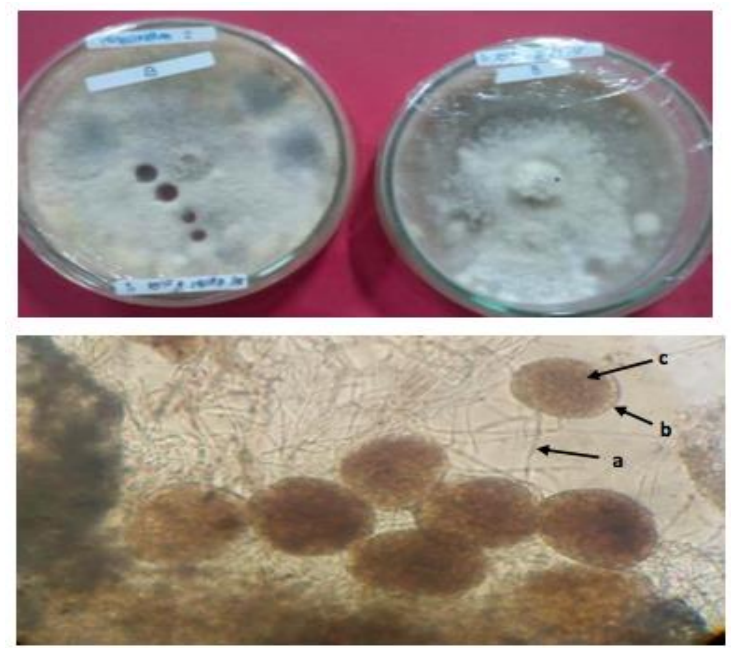

Gambar 6. Zygomycota 1 pada tanah endapan Danau Tempe

Hal ini seperti yang dinyatakan oleh (Barnett \& Hunter, 1988) bahwa zygomycota mempunyai miselium, tidak mempunyai septa (sebagian kecil sub grup mempunyai septa), beberapa spesies mempunyai dua bentuk yaitu hifa dan yeast (dimorfik) sporanya biasa menggunakan spora non motil yang dibentuk didalam sporangium dan diletakkan pada sporangiofot. Sporangium biasanya agak besar dan berbentuk globose. 


\section{KESIMPULAN}

Berdasarkan hasil penelitian, maka dapat disimpulkan bahwa:

1. Mikroba yang ditemukan pada kompos, endapan tanah danau tempe dan exfarm adalah Aspergillus sp. Penicillium sp., dan Zygomycota.

2. Karakteristik yang ditemukan dari tiap cendawan dapat dilihat dari pengamatan makroskopis dan mikroskopis serta kecepatan tumbuhnya.

\section{Saran}

Perlu dilakukan penelitian lanjutan untuk menguji efektifitas cendawan yang ditemukan sebagai aktivator dalam mendegradasi bahan organik pada pengomposan.

\section{PUSTAKA}

Abadi AL. 2003. dalam Lina Budiarti. 2014. Kelimpahan Cendawan Antagonis pada Rhizozfer Tanaman Kacang Panjang dilahan kering. Indralaya Sumatera Selatan.

Barnett H. L and hunter B. B. 1998. Illustrated Genera of Imperfect Fungi. U.S.A

Bower. 1978. dalam hakkar. 2015. Keanekaragaman mikroba tanah pada lahan sayuran organik dan non organik. Jurusan Hama dan Penyakit Tumbuhan Universitas Hasanuddin. Makassar

Deptan. 2009. dalam Mulyadi. 2008. Karakteristik Kompos dari Bahan Tanaman Kaliandra, Jerami Padi dan Sampah Sayuran. Program Studi Ilmu Tanah Fakultas Pertanian. IPB. Bogor

Erikson et al, 1989 dalam Saraswati 2005. Organisme Perombak Bahan Organik. http://balittanah.litbang.deptan.go.id./ dokumentsi/buku/pupuk/pupuk10.pdf. diakses pada 11 juli 2015

Ihwan M. 2015. Isolasi Cendawan dari Rhisosfer Kakao (Theobromae L. cacao) yang dikelola secara Organik, Semi-Organik dan Non-Organik. Ilmu Hama dan Penyakit Tanaman. Fakultas Pertanian Universitas Hasanuddin, Makassa 